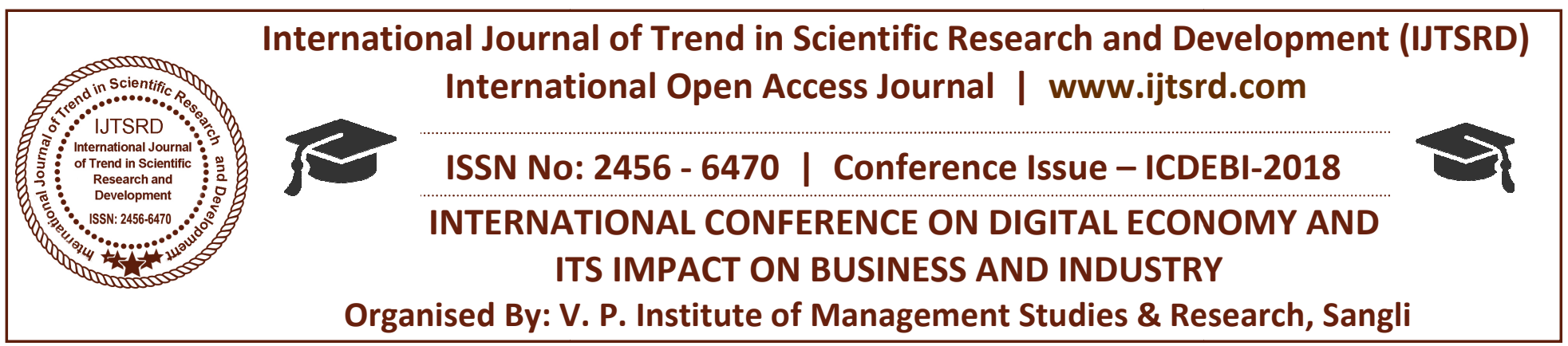

\title{
E- Health: A Way of Digitalization
}

\author{
Ms. Rajani. P. Shinde \\ Assistant Professor, V. P. Institute of Management Studies \& Research, Sangli, Maharashtra, India \\ Affiliated to Shivaji University, Kolhapur, Maharashtra, India
}

\begin{abstract}
Digitilsation is the wave which is been surrounding in the different areas, fields of the business process and the services. The digitalization has its own impact, the pros and cons on the basis of the premises where it has been initiated, developed and the results we get after the whole journey is been completed.
\end{abstract}

The paper puts the lights on the digitalization in field of health care services, as the digitalization had put the steps in different markets the health center is one of the services were it can be also initiated. As the there is traditional approach of people or the patients to take heath services but the new way of digitilsation will also help to the health services to provide the timely services to the patience instead of having the use of traditional way of searching the specific hospitals for the specific treatment, to take the appointments for specific treatment , of specific doctors which led to sometime inefficiency, time consuming for the treatment of patient etc.

The paper highlights the points which can be taken into consideration to start with Electronic health care services, the various different platforms and the models which can be used by the health center to widen the scope of this type of services, searching appointment and scheduling at tip of finger ,application and the worth, the reliability which can defined the patients acceptances towards the services, anticipating the challenge and the constraint which might hamper the mobility of the services.

Keywords: Digitalization, E-Health care services

\section{INTRODUCTION}

Digitalization is bringing the change in carrying out the services. E- Health is an indeed the innovation enhance the way of automate the process and operation of health care organization which take care about the efficient and effective process , improved accessibility and human interaction which in turn offering an assistance with routine medical tasks and provide easy navigation. The Information Technology will change way of perception of the health care, transforming the relation between the patients and the centers.

The initiated of E-Health services start with the creating the value by understanding the patients needs and the myths surrounding them. Also they should indentify the customer segments and define the position of the services strategically to meet the estimated patient's needs and the demands. One of the way to retain and to attract the customer health care should not only focuses the innovation which points towards the features and design, content on electronic boards but the to work on the actionable services of digitalization thereby having robust and value added features of digitalization by transforming the way of the providers that the heath care center staff and the services and patients functions with interactions which enhance the medical care service accessible to everyone without any geographical barriers by ensuring the acceptance widely

The success to adopt the digitization services depends on the understanding patients digital preferences in the both channel and the services to understating in depth the health care center should take the review from the patients and the people from the different 
age group, genders, incomes levels or purchasing power , geographical location i.e. area, region covering the urban, rural and metropolitan, the operating knowledge of the electronic ways which will give the actionable insights information regarding what the patients exactly expects ,their wants which will help to build the health care departments to build the models and the strategy of $E$ Health patients services.

\section{Some of the models can be anticipated as,}

\section{People unwillingness to accept the Electronic services about the health care :}

As the medical area is more sensitive and the emotional from point of the perception, patients may not be the fast to adopt but they might adopt it in slowly for reason that digital health care services meet their needs and level of quality they might be expecting from the digitalization and so that it might be align to the traditional approach of the services.

So the myth should be clear removed from the minds of the people by giving proper digital service at right time and with right treatment and the suggestion which is based on the data the patients has been feed into the systems with the particular channel or mode.

\section{The preference channel :}

The health care organization should design the models of the channels which are relevant, user friendly mode, easy to operate by the any type of people, minimum cost factor, time saver, response in minimum time, minimum error in operating the process, cheap mode.

Considering the interaction with health organization with whoever the entity it is it might be an executive of heath care center, doctors, pharmacies

\section{Sources to have preference will be as,}

A. Websites or online portal of health care center or hospitals

B. E- Mailingsystems of health care centers

C. Smartphone's App : to define the process/steps in electronics systems

D. Telephones interaction with the mode of video and audio techniques

\section{To build proper STP analysis}

As most of the digital services are adopted quickly by the young generation so it might be the limitation that the digital service utilization will be deprived from the other segment as senior citizens, Adult resemble to age group of more than 50 , so the another fact that health care center should research on the age group factor such that it will give the real fact for the segmentation, target and positioning the digital services in proper way.

Based on the digital interaction the age group chart:

\begin{tabular}{|c|c|c|c|c|c|c|}
\multicolumn{7}{|c|}{ Age group } \\
\hline Channel & $\begin{array}{c}18- \\
30\end{array}$ & $\begin{array}{c}30- \\
40\end{array}$ & $\begin{array}{c}40- \\
50\end{array}$ & $\begin{array}{c}50- \\
60\end{array}$ & $\begin{array}{c}60- \\
70\end{array}$ & $\begin{array}{c}70 \\
\text { and } \\
\text { above }\end{array}$ \\
\hline $\begin{array}{c}\text { Portal } \\
\text { view }\end{array}$ & & & & & & \\
\hline $\begin{array}{c}\text { Email } \\
\text { Social } \\
\text { Media }\end{array}$ & & & & & & \\
\hline $\begin{array}{c}\text { Smart } \\
\text { phones } \\
\text { APP }\end{array}$ & & & & & & \\
\hline Telephone & & & & & & \\
\hline
\end{tabular}

This chart will help to give the information of those age group who will be willing to adopt the digitalization services of health care.

\section{Features on mobile App :}

The health care organization should create a mobile solutions that will help to serve the target audience such that app should focus on prenatal health.

The digital should also be user friendly for the usage with the simple questions with clearly stated with the relevant options and too much of difficult and lengthy question about health problem.

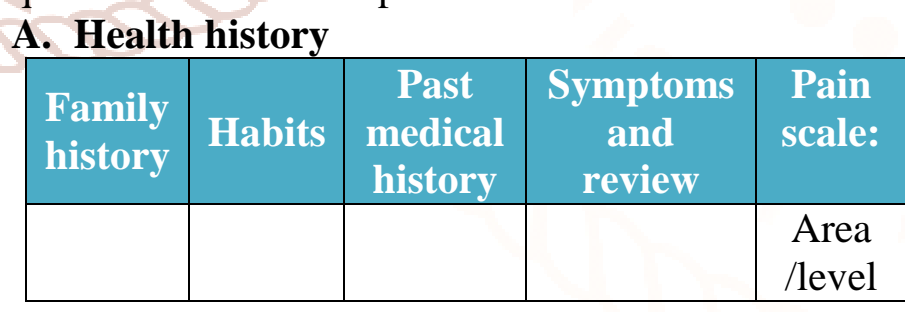

\section{B. Personal information:}

Age, Kind of job, No. of working hours, Married/ Unmarried status, past medical history.

\section{Medication History:}

Type of diagnosis, Medicines details, duration and no. of intake of medicines, earlier which recommended hospital and Doctor 
D. Allergies: Kind of Allergies.

1. To evaluate the awareness in the people

The following things should be evaluated to anticipate the awareness

A. Awareness of online health care services

B. Ability to execute the process and to receive the services with online platform

C. Fast availability of the search entity, the person or hospital route, prescribed location

D. Percentage of Accessibility of digital services

E. Review of clarity, accuracy and integrity of the online information

The application or the significant can be write in the following ways----

1. Improving the productivity and the patient care:

By giving the vital importance to the areas of inpatients, theatres and outpatients. Focusing on improving the review \& feedback of the online treatment provide, different modes for digital interactions, use of primary data for the further uses of theatres process and to improve the flow of process with simple steps and procedures

Also responding to "What If Questions", "Frequently Asked Questions", by design the staff with skills of interaction and coaching which enhance that the health care center helps them to take the better decisions and to take clinical changes.

\section{To monitor the process}

By having the eyes on the percentage and no of patients that have demanded to take digital health care services, monitoring the booking appointment for the specific treatment, for a specific day and time and for the doctors, checking for fulfilment of pre operative works So that the digital health care process will work with minimum error and the trouble for the patients and for the health care center

\section{The health care center should stay focused}

$>$ For the new improvement the in the digital channel, features, value added services as digital payments, digital reports and forms, remote patients monitoring, consultation via mobile communication etc

$>$ Making the use of business intelligence tools to visualize the data and to improve the productivity and the efficiency

Making the use of cloud computing application to give new face the information technology that enables the systems to cost less to build, execute and to maintain

\section{Conclusion:}

The E- health systems will be having the application to the patients through the utilization of the different models that is medical app on the mobile phones, visiting to the portal of the specific hospital, virtual interactions with the doctors and other entities.

Thus the digitalization is the way of new technologies which help to enables a new, better and more efficient ways to serve the health care service to all the people without having a area constraint.

\section{Reference:}

1. www.infinitiresearch.com

2. https://hitconsultant.net/2017

3. www.paconsulting.com 